\title{
$\operatorname{Me} / 6 / 6 / 0,0-2$
}

DOE/ER/61060--2

DE92 016970

\section{- Second Annual Progress Report of the Millimeter Wave Cloud Profiling Radar System (CPRS)}

\author{
Andrew L. Pazmany, Stephen M. Sekelsky', \\ and \\ Robert E. McIntosh (Principal Investigator) \\ Microwave Remote Sensing Laboratory \\ University of Massachusetts \\ Amherst, MA 01003
}

\section{DISCLAIMER}

This report was prepared as an account of work uponsored by an agency of the United States Government. Neither the United States Covernment nor any agency thereof, nor any of their employeses, makes any warranty, express or implied, or assumes any legal liability or responsibility for the accuracy, completeness, or usefulness of any information, apparatus, product, or process disclosed, or represents that its use would not infringe privately owned rights. Reference herein to any specific commercial product, process, or service by trade name, trademark, manufacturer, or otherwise does not necessarily constitute or imply its endorsement, recom. mendation, of favoring by the United States Government or any agency thereof. The views and opinions of authors expressed herein do not necessarily state or reflect those of the United States Government or any agency thereof. 


\section{Introduction}

The Cloud Profiling Radar System (CPRS) is a single antenna, two frequency $(33 \mathrm{GHz}$ and $95 \mathrm{GHz}$ ) polarimetric radar which is currently under development at the University of Massachusetts (UMASS). This system will be capable of making four dimensional Doppler and polarimetric measurements of clouds. This report gives details about the status of the various subsystems under development and discusses current research activities. 


\section{Field Test of the $95 \mathrm{GHz}$ Polarimeter}

The $95 \mathrm{GHz}$ section of the CPRS was completed in December 1991. The instrument was integrated with the Polarimetric Radar Control and Data Acquisition system (PRACDA), and was tested with a twelve inch lens antenna at the University of Massachusetts calibration site. In March of 1992 the Microwave Remote Sensing Laboratory and researchers from the University of Wyoming's Atmospheric Science Department participated in a second joint experiment at Elk mountain, Wyoming, where the $95 \mathrm{GHz}$ polarimeter was used to perform polarimetric and Doppler measurements on a wide range of cloud and snow particle types. The experiment took place at the University of Wyoming (UW) Elk Mountain Observatory (12,000 ft. above sea level), where extensive ground truth was provided by the ground sensors operated by the UW Atmospheric Science group. Weather conditions were recorded along with two-dimensional shadow images of the particles from a Particle Measuring System (PMS) probe mounted in an outdoor wind tunnel.

Fully polarimetric data obtained during the Wyoming experiment shows the $95 \mathrm{Ghz}$ polarimeter's sensitivity to snowflake shape, preferred orientation, and degree of randomn sss. Figures 1. and 2. show the Mueller matrix and polarization signatures for predominantly small, unrimed planar crystals and for rimmed crystals having more spherical shapes. The co-polarized signature of the planar crystals has a larger dip at 90 degree orientation than the rimmed crystals. This dip in the co-polarized signature characterizes ice particles having nonsymmetrical shapes that are horizontally aligned. The percent-polarization signature also decreases because of reduced shape symmetry and randomness in particle orientations.

Images showing cloud structure and variation of the polarization signature are seen in Figures 3, 4, and 5. Figure 3. shows the radar reflectivity which depends on particle type, size, shape, and cloud density. Increasing reflectivity with elevation angle suggests that nonsymmetrical crystals are horizontally oriented and their cross sections increase with elevation angle. This explanation is supported in Figure 4, which is an image of the ratio between the horizontal and vertical radar cross sections. This ratio is called the differential reflectivity and Figure 4 , shows that the difference between the horizontal backscatter and the vertical backscatter 
is greatest when the radar views the cloud particles from the side and the ratio disappears as the radar views the particles from below. The ratio of the received cross-polarized and co-polarized power imaged in Figure 5 also shows that cross polarization is greatest when the radar irradiates the cloud particles from the side. The percent polarization as a function of elevation angle in Figure 6 also shows the effect of nonsymmetrical crystals..

The low phase-noise and high pulse repetition frequency $(80 \mathrm{KHz})$ capability of the polarimeter made full spectrum Doppler measurements possible. Figure 7. shows how the cloud particles flow within the sampled volume

Dote Morch 31, 1992

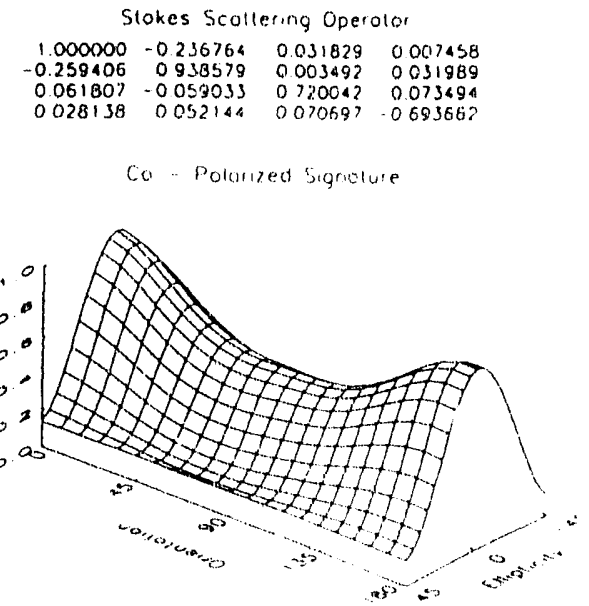

Percent -.. Polorizotion Sigrotute

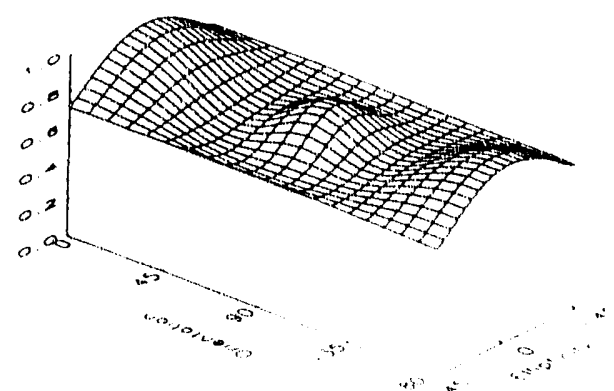

Figure 1.

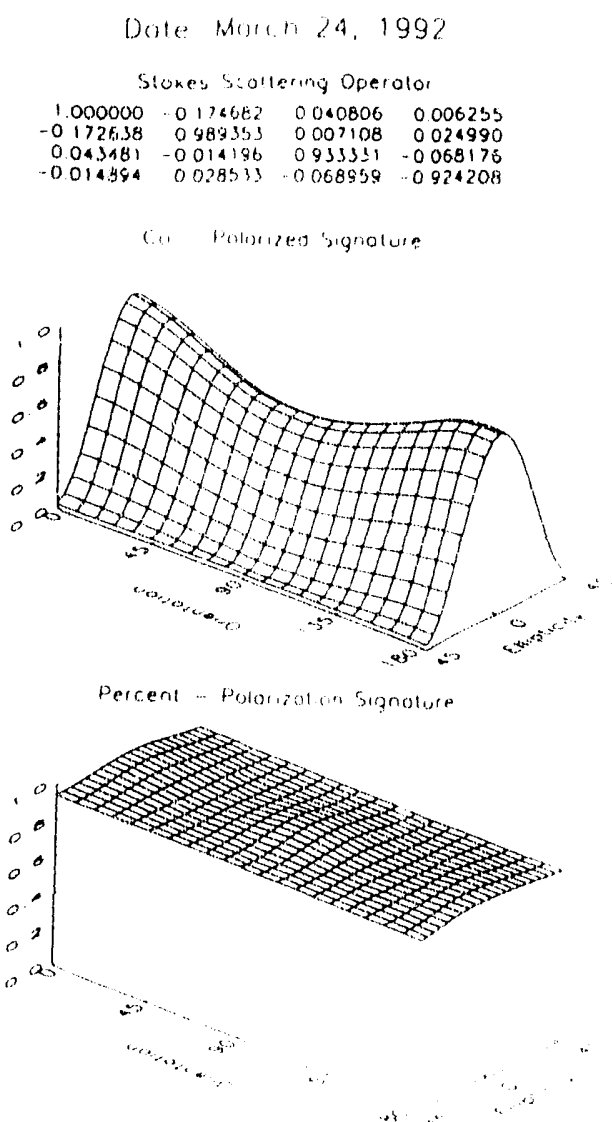

Figure 2

Figures 1 and 2: Stokes scattering operator, Co-polarized signature, and the Percent-polarization signature for two types of snow particles. Particles of Figure 1 are plate and stellar crystals, and Figure 2 are rimmed stellar crystals and aggregate snow flakes. 


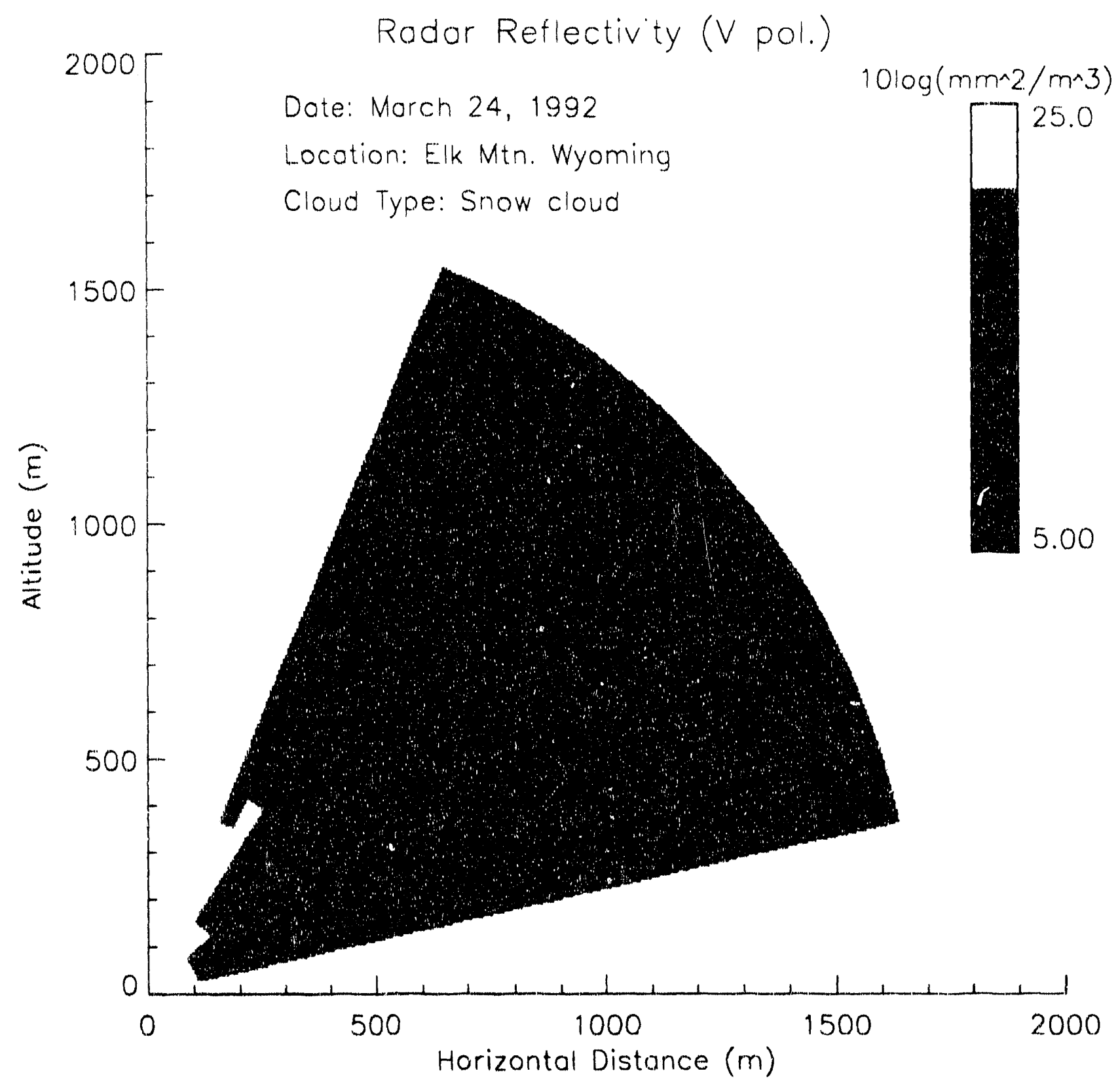

Figure 3: Radar reflectivity $\left(\mathrm{mm}^{\wedge} 2\right)$ per unit volume $\left(\mathrm{m}^{\wedge} 3\right)$. 


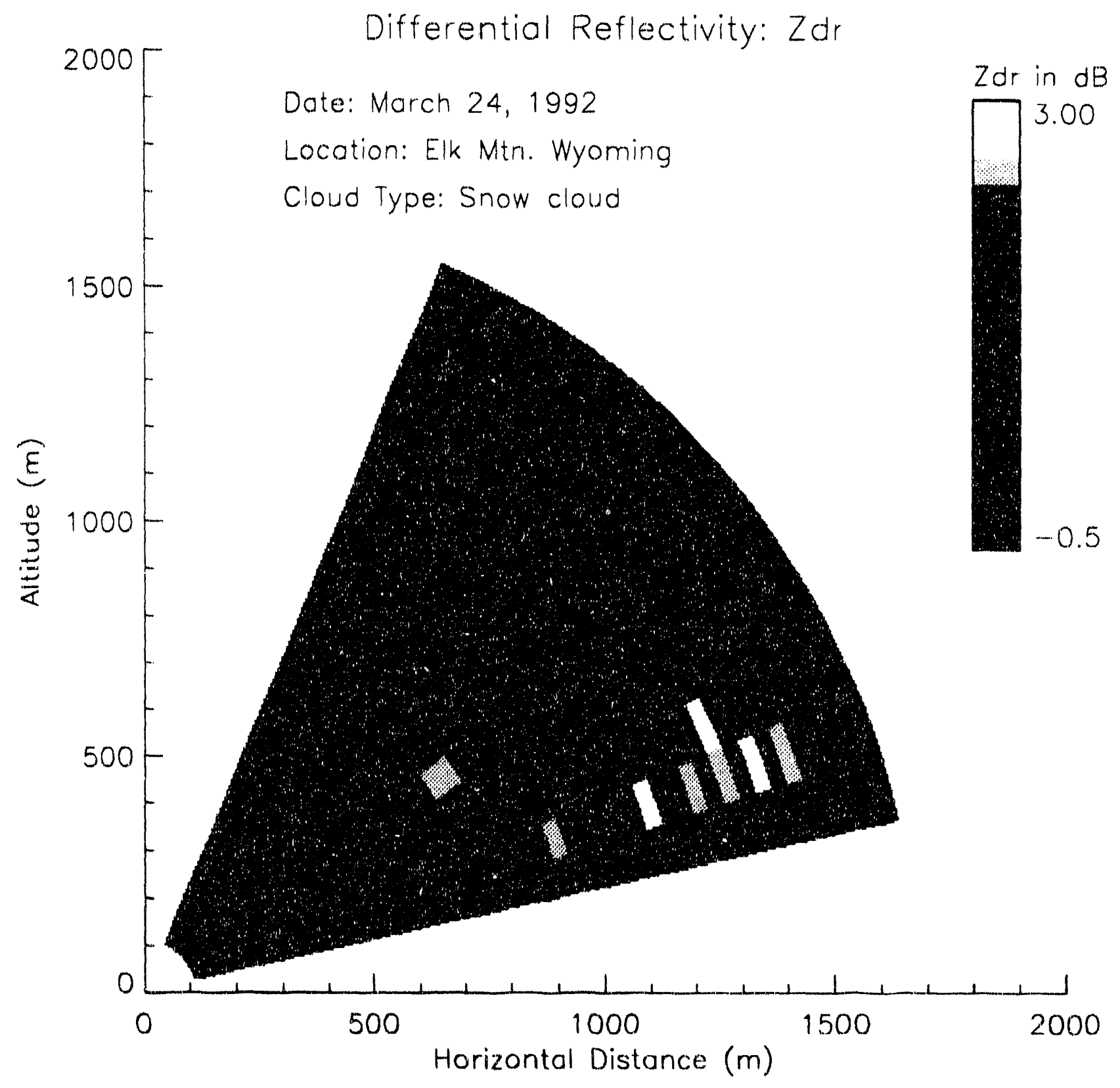

Figure 4: Differential reflectivity (the ratio between the horizontal and vertical radar cross section). 


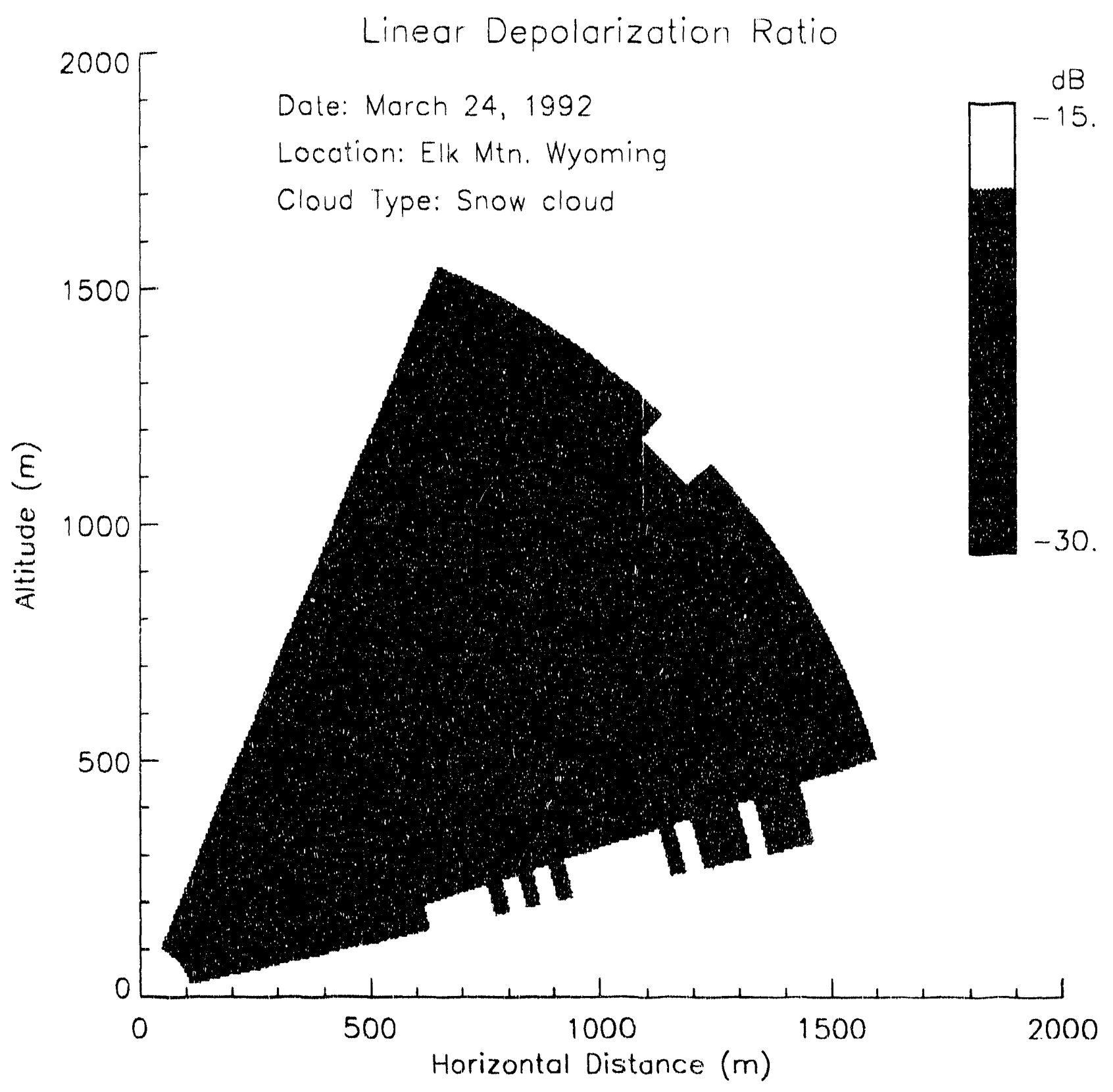

Figure 5: Linear depolarization ratio (ratio of the received cross-polarized and co-polarized power). 


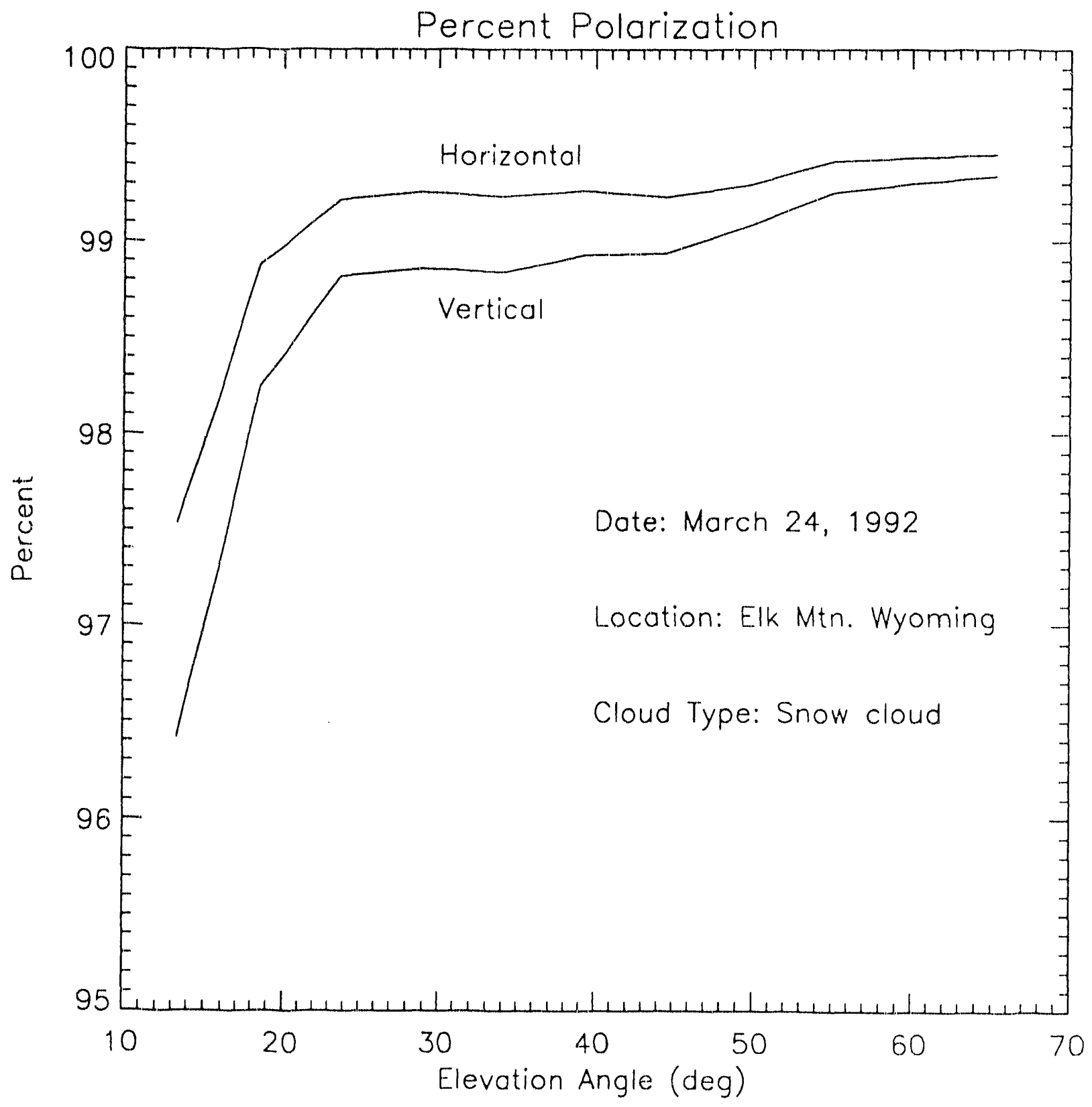

Figure 6: Percent polarization as a function of elevation angle. 


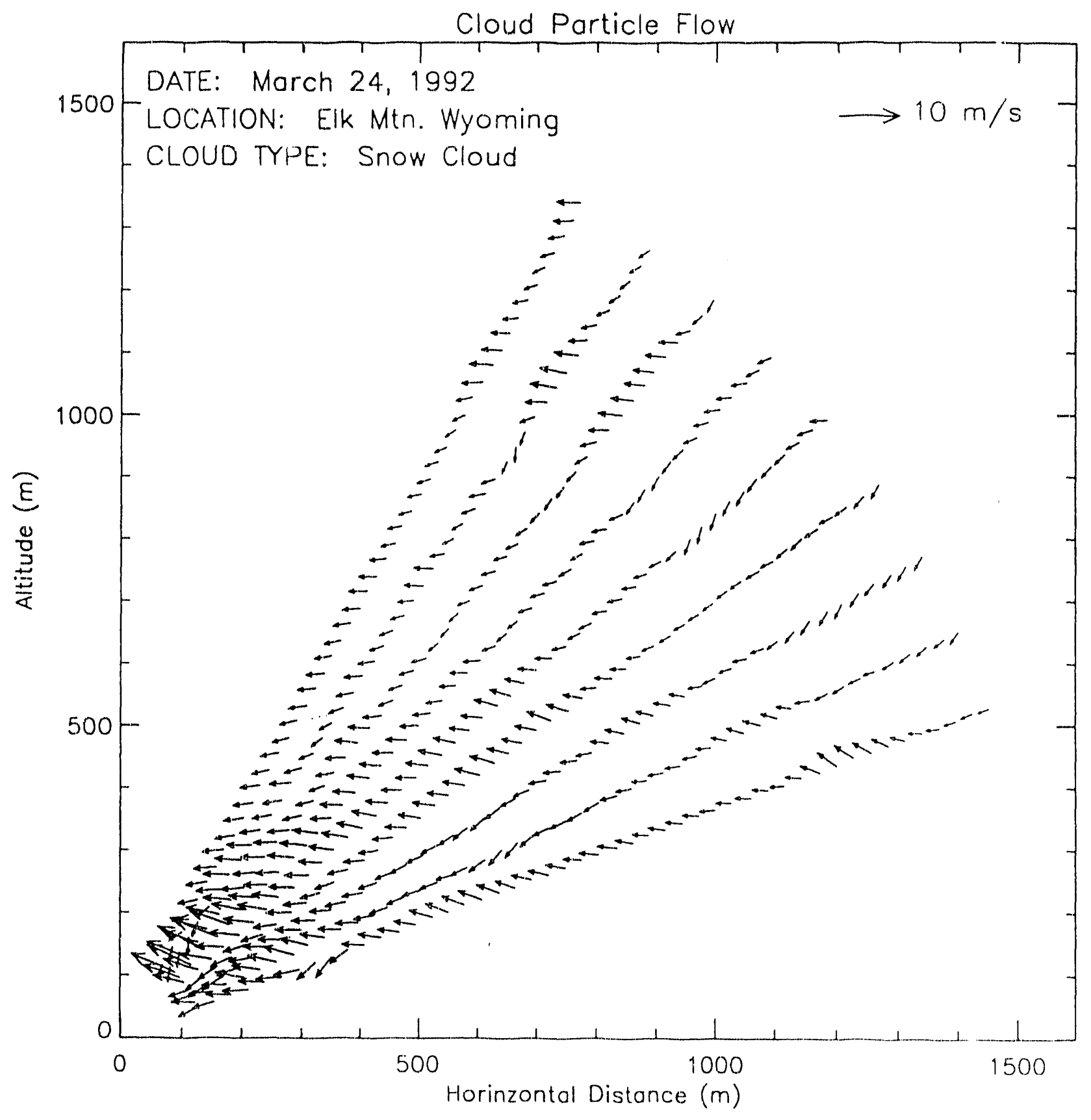

Figure 7: Cloud particle flow. 


\section{Upcoming Experiments Involving the $95 \mathrm{GHz}$ Polarimeter}

In August of 1992 the Microwave Remote Sensing Laboratory will participate in another experiment with the UW Atmospheric Science Department. The $95 \mathrm{GHz}$ polarimeter will be installed on the UW King Air aircraft and will collect polarimetric data of clouds in the Wyoming area. The aircraft is equipped with weather sensors and PMS probes, so extensive ground truth will be available for comparison with the polarimetric radar data.

Ground-based polarimetric measurements of clouds are also planned for this summer. The Microwave Remote Sensing Laboratory will install a four foot diameter dish on the $95 \mathrm{GHz}$ polarimeter to obtain $12 \mathrm{~dB}$ of additional sensitivity and improved angular resolution for the imaging of clouds. Some measurements will take place at the University of Massachusetts at Amherst and some may take place at the DOE CART site in Oklahoma, if there are adequate insitu cloud data available or if it possible to operate the ground-based $95 \mathrm{GHz}$ radar simultaneously with other ARM IDP remote sensors. 


\section{Status of the $33 \mathrm{GHz}$ Polarimeter}

The $33 \mathrm{GHz}$ polarimeter portion of the CPRS system is currently being assembled and completion is anticipated early in the fall of 1992. Since the writing of the first technical progress report the method used to obtain coherency in the radar has changed. A revised block diagram of the high power section of the transmitter is shown in Figure 7.

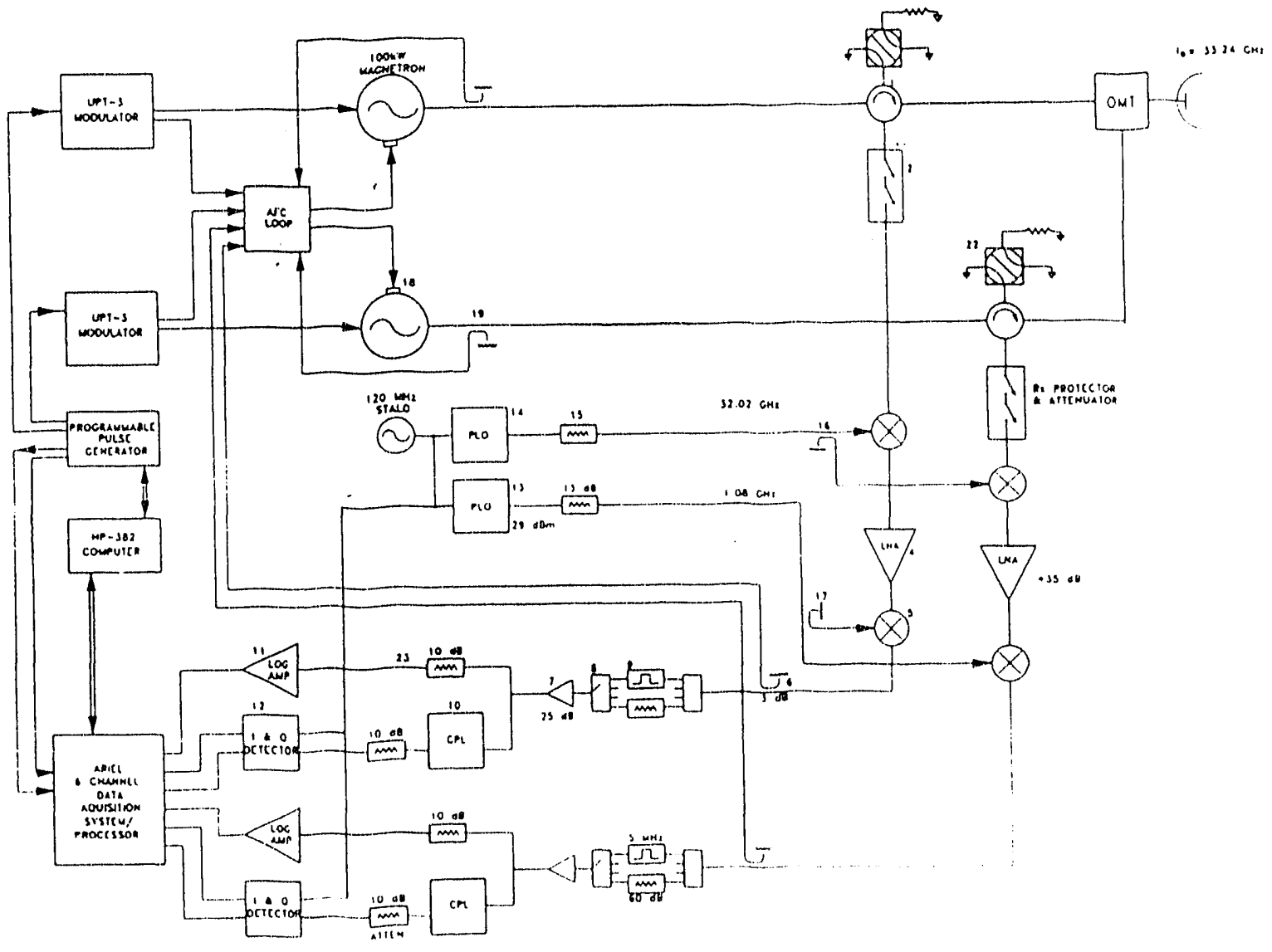

Figure 8: $33 \mathrm{GHz}$ Polarimeter. 


\section{Status of the Dual-Frequency Polarimetric Antenna}

Figure C depicts the CPRS antenna system. Except for the feed horn, the design is complete. Two prototypes of the feed horn are currently being evaluated at the UMASS Antenna Laboratory. Although one type will provide the desired feed pattern, it requires an additional corrective lens at $95 \mathrm{GHz}$ which adds loss. It is hoped that a simpler confriguration can be used. Although both are corrugated scalar feeds, they use different mechanisms to focus the $95 \mathrm{GHz}$ beam. The first, a wide flare angle horn, focuses both the $33 \mathrm{GHz}$ and $95 \mathrm{GHz}$ signals so that a thin, low loss dielectric pressure cap can be used. The other, a narrow flare angle horn, requires a thick correcting lens/pressure cap to fully focus the $95 \mathrm{GHz}$ beam.

Prototypes of the $33 \mathrm{GHz}$ orthomode transducer show a measured cross polarization isolation of over $35 \mathrm{~dB}$ with a $95 \mathrm{GHz}$ dielectric rod waveguide running down their centers. The one meter lens and reflector plate are being machined and a supporting framework is being assembled. These components and the feed horn should be ready for integration and testing in August 1992. After preliminary testing at UMASS, the antenna will be taken to an industrial antenna range where co-polarized and cross-polarized radiation patterns will be measured. 


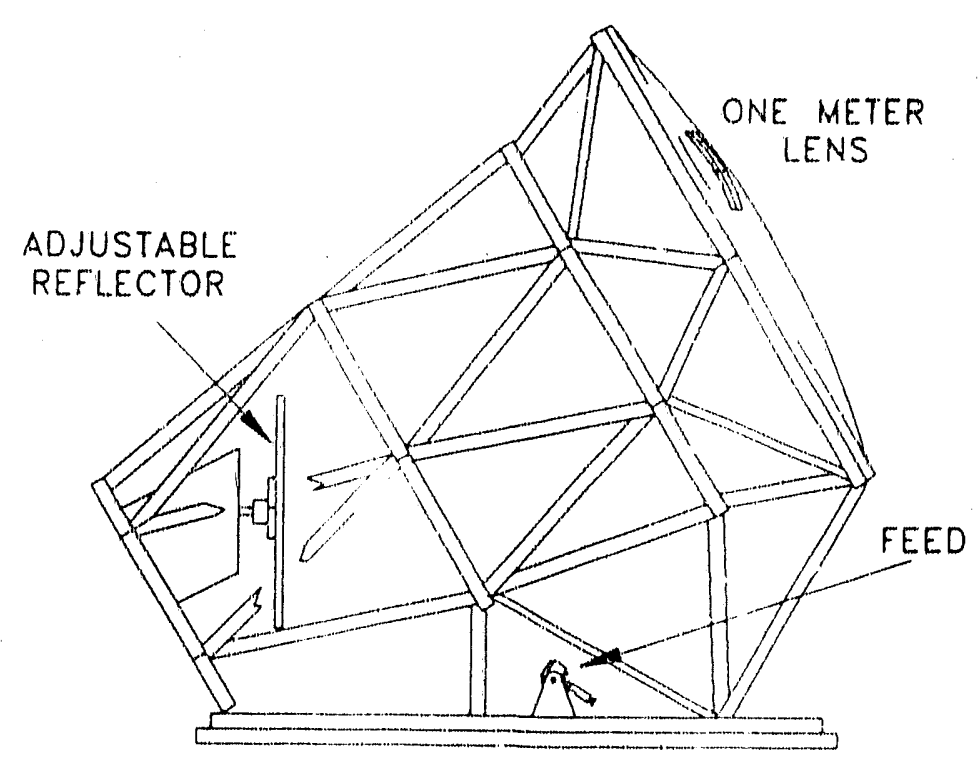

Figure 9: CPRS antenna structure.

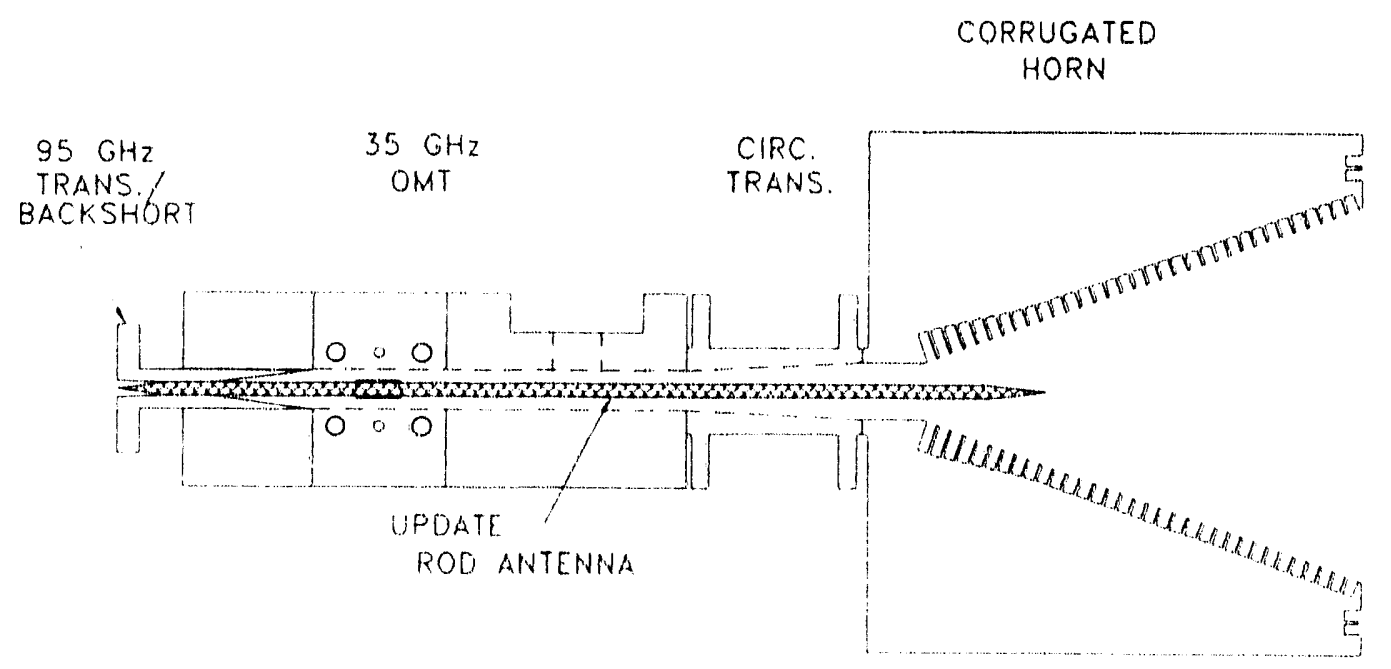

Figure 10: Wide flare angle feed and OMT 
DATE

FILMED

$813 / 192$ 
